PAPER

\title{
Elective stenting for symptomatic middle cerebral artery stenosis presenting as transient ischaemic deficits or stroke attacks: short term arteriographical and clinical outcome
}

\author{
J K Kim, J Y Ahn, B H Lee, Y S Chung, S S Chung, O J Kim, W C Kim, J Y Joo
}

J Neurol Neurosurg Psychiatry 2004;75:847-851. doi: 10.1136/jnnp.2003.019570

See end of article for authors' affiliations

Correspondence to: Dr J Y Ahn, Department of Neurosurgery, Pundang CHA Hospital, 351, Yatap-dong, Sungnam 463-712, Korea; iyahn@cha.ac.kr

Received 6 June 2003 In revised form

15 September 2003

Accepted 4 October 2003
Background: Although stent assisted angioplasty is an effective treatment for coronary and peripheral arterial disease, its efficacy in intracranial arteriosclerotic disease has not been verified.

Objectives: To assess the radiographic and clinical outcome of stent assisted angioplasty for symptomatic middle cerebral artery (MCA) stenosis.

Methods: We attempted stent assisted angioplasty in 14 patients with symptomatic high grade stenosis $(>60 \%$ ) on the proximal portion of the MCA, who had experienced either recurrent transient ischaemic attacks (TIAs) resistant to medical therapy or one or more stroke attacks. Patient records were analysed for angiographic characteristics, degree of stenosis, pre-procedural regimen of anti-platelet and/or anticoagulation agents, use of devices, procedure related complications, pre-operative and post-operative single photon emission computed tomography (SPECT) findings, and clinical and radiographic outcomes. Results: Stent assisted angioplasty was successfully performed in 8 of 14 patients without any serious complications and unsuccessful in 2 of 14 patients due to the tortuous curve of the internal carotid artery siphon. Four patients had complications. Two patients had an arterial rupture; one patient was rescued by an additional stent and balloon tamponade, the other patient died. Complications in the other two patients included thrombotic occlusion and distal thrombosis. Residual stenosis was less than $50 \%$ in diameter in all the patients. All eight patients who underwent follow up cerebral angiography had no restenosis. Follow up SPECT showed improved perfusion in the affected MCA territory in all the tested patients with TIA and in one of three stroke patients. Using the modified Rankin Scale at follow up, four of five TIA patients and five of six stroke patients were assessed as functionally improved or having a stable clinical status.

Conclusion: Although the re-stenosis rate in stent assisted angioplasty seems to be better than in primary balloon angioplasty as reported previously, the complication rate is still high. Elective stenting is an alternative therapeutic method for the prevention of secondary ischaemic stroke in stroke patients with MCA stenosis, and seems to be a potentially effective but also hazardous therapeutic technique in patients with recurrent TIAs. This study indicates the need for randomised control trial data of this intervention. Additionally, long term follow up data and additional clinical experience are required to assess the durability of this procedure.
$\mathrm{T}$ he most recognised stroke syndromes occur in the middle cerebral artery (MCA) region, in large part related to the extensive MCA blood supply to the lateral hemisphere and deep basal ganglia area. Although embolism is the predominant mechanism affecting the MCA, primary arteriosclerosis at this site occurs in African Americans and Asians and may play a significant role in MCA occlusive disease, compared with whites. ${ }^{12}$ Many patients with this disease have recurrent cerebral ischaemic events despite standard medical therapy with anti-platelet agents or oral anticoagulants. In the Extracranial/Intracranial Bypass Trial, patients with symptomatic MCA stenosis randomised to medical therapy had annual ipsilateral stroke rates of $7.8 \%$ and total stroke rates of $9.5 \%{ }^{3}{ }^{4}$ Only about one third of patients had a warning transient ischaemic attack (TIA) prior to stroke. ${ }^{3}$ The most common presentation was a stroke attack without a warning TIA.

In these patients, the stenosis had been slowly growing as a result of an arteriomatous rather than a thrombotic process. Anticoagulants would therefore appear to aid only in prevention of an abrupt final occlusion caused by thrombus, and not in preventing progression of the disease to an inevitable occlusion. ${ }^{5}$ The high recurrent stroke rates indicate the need for more for more aggressive treatment methods for patients with symptomatic MCA arteriosclerotic stenosis. Percutaneous transluminal angioplasty (PTA) has recently been proposed as a promising treatment for patients with ongoing cerebral ischaemic events despite standard medical therapy..$^{5-8}$ However, PTA has had the problems of abrupt closure due to complications such as intimal damage, elastic recoil, and thrombosis. ${ }^{5}$ Abrupt closure in the MCA often cannot be tolerated, resulting in stroke or death. Stents have improved these complications in other vascular beds, ${ }^{9}$ and advantages of stent assisted angioplasty include exclusion of the plaque and regions of dissection from the vessel lumen, and prevention of vessel recoil and rupture. ${ }^{10}$ Therefore, the availability of recently introduced flexible stents, the development of potent antiplatelet inhibitors, and increasing evidence from experimental and clinical studies of intracranial stents have encouraged the use of stents in the management of ischaemic intracranial cerebrovascular disease. ${ }^{10} 11-14$

The purpose of this study was to investigate the effectiveness, safety, and short term outcome of stent placement for

Abbreviations: ICA, internal carotid artery; MCA, middle cerebral artery; PTA, percutaneous transluminal angioplasty; SPECT, single photon emission computed tomography; TIA, transient ischaemic attack 
the treatment of refractory symptomatic MCA arteriosclerotic stenosis.

\section{METHODS}

During a 35 month study period between February 2000 and September 2002, 14 consecutive Asian patients underwent planned stent assisted angioplasty of symptomatic arteriosclerotic stenosis of the MCA. Significant stenosis was defined as $60-99 \%$ stenosis on angiograms. Arteriosclerotic lesions were classified, according to the method of Mori et al, into three groups on the basis of lesion morphology. Patients were included if they had one of the following three conditions: (a) recurrent TIAs referable to MCA stenosis that were unresponsive to medical therapy using therapeutic dose of aspirin, ticlopidine, clopidogrel, or warfarin; $(b)$ significant perfusion problems in MCA regions evidenced by decreased perfusion reserve on single photon emission computed tomography (SPECT); and (c) infarction at the border zone of the MCA region, which was considered to be related to haemodynamic insufficiency. Exclusion criteria were: (a) presence of significant arteriosclerotic lesions in the arteries proximal to the MCA; $(b)$ emboligenic heart disease; $(c)$ serious medical problems such as heart or renal failure; and (d) coexisting severe stenosis or occlusion of the $M_{2}$ or $M_{3}$ segments of the MCA. In two patients, the selected stent was not able to reach the target because of extreme tortuosity; these patients were excluded from further analysis. The patient population was composed of seven male and five female subjects (age range 42-76 years; mean 58 years). All patients had a stenotic lesion that was considered to be directly responsible for the symptoms, and they were selected for stent assisted angioplasty on the basis of several factors, including failure or contraindication of medical treatment; non-feasibility, failure, or contraindication of surgery; poor neurological grade; and poor medical status. The patient's family gave informed written consent for cerebral arteriography, intracranial balloon angioplasty, and intracranial artery stent placement.

Patients received aspirin and clopidogrel (Plavix; Sanofi) 72 hours before the procedure, combined therapy was continued for 6 months, and aspirin was continued indefinitely. All the patients underwent pre-operative CT or MR imaging or both and cerebral digital subtraction angiography. Eleven of 14 patients underwent pre-operatively brain ${ }^{99}$ mTcexametazime (Ceretec; Amersham) SPECT. Seven of 11 patients post-operatively underwent SPECT scans within 1 week of surgery. Angiographic follow up was conducted at 6 and 12 months. No patient was lost to follow up monitoring except one who died. Employing the criteria developed by the Warfarin-Aspirin Symptomatic Intracranial Disease study, ${ }^{15}{ }^{16}$ we calculated the stenosis rate on angiograms before and immediately after stent assisted angioplasty and at follow up to compare the diameter of the vessel at the site of greatest narrowing with the diameter of a normal artery distal to the lesion. A technically successful stent assisted angioplasty was defined as one leaving a residual stenosis of $50 \%$ or less without any serious complications. The post-operative neurological and functional status was evaluated by two neurologists at intervals of 2 months. To assess the post-operative functional status at admission, at discharge and at last follow up respectively, we defined a 6 point scale (modified Rankin Scale ${ }^{17}$ ).

\section{Procedure}

The length and diameter of a lesion were measured on arteriograms obtained with the lesion positioned at the isocentre. Because images obtained with digital subtraction angiography in our institution showed lesions to be 1.4 times larger at the isocentre, a $14 \mathrm{~mm}$ scale was placed on an image intensifier entrance plane with a grid to indicate a $10 \mathrm{~mm}$ scale on the angiograms. Before, during, and after transluminal stent assisted angioplasty for stenosis, patients were given heparin intravenously (activated partial thromboplastin time 2-3 times baseline) to avoid thrombus formation, and isosorbide dinitrate ( 1.25 to $2.50 \mathrm{mg}$ ) was injected as a single rapid bolus into the internal carotid artery (ICA) through a guiding catheter (8F MPA; Cordis Co. Miami, FL, USA) to prevent catheter induced vasospasm. All procedures were performed under neuroleptic anaesthesia with propofol. A 0.014 inch guide wire (Wizdom-14; Cordis Co) was navigated across the target site. The S-660 stents (MedtronicAVE, Santa Rosa, CA, USA) were used in all cases except in the first case which used the GFX coronary stent (AVE Inc., Santa Rosa, CA, USA). The main principle of stent placement was that a balloon of a smaller size than the diameter of the vessel should be gradually dilated with lower than nominal pressure. The stent was deployed at 5-8 $\AA$ below the nominal pressure for 20-30 seconds. After the balloon was deflated, the result was verified and, eventually, inflation was repeated (fig 1). After the intervention, each patient underwent a complete neurological examination, after which their neurological status was monitored closely for 24 hours. Heparinisation was discontinued after 24 hours post-treatment but was not reversed by the antidote. The sheath used to introduce the stent into the artery was removed after the procedure.

\section{Statistical analysis}

Data analysis was performed by using SPSS/Windows version 10.0 statistical software; statistical significance was set at $\mathrm{p}<0.001$ (two tailed assessment). Paired Student's $t$ test was used to determine whether there were any differences in percentage diameter stenosis on the angiograms obtained before and immediately after treatment and at the last follow up.

\section{RESULTS \\ Subjects}

The demographic and clinical features of the patients are presented in table 1 . Lesion laterality is $1: 2$ (right:left), mean lesion length $6.4 \mathrm{~mm}$ (range 3-14 mm). Brain SPECT showed decreased perfusion in the affected MCA territory in all the tested patients with TIAs. In five stroke patients,

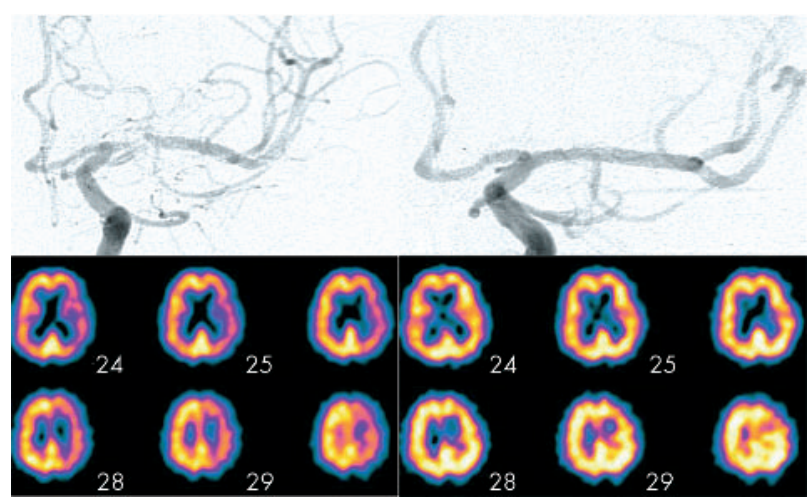

Figure 1 Stent assisted angioplasty for the symptomatic left middle cerebral artery stenosis (Type B according to Mori's classification). (A) Initial angiogram shows a high grade $(90 \%)$, eccentric, focal (length 5$10 \mathrm{~mm}$ ), arteriosclerotic stenosis of the left $M 1$ segment. (B) Follow up angiogram obtained after 12 months demonstrates no signs of restenosis. (C) Brain ${ }^{99} \mathrm{mTc}$-exametazime (Ceretec; Amersham) single photon emission computed tomographic (SPECT) scans show diffusely reduced perfusion in the left cerebral hemisphere pre-operatively. (D) Follow up SPECT scan obtained within 24 hours after stent deployment had improved to nearly normal perfusion. 
brain MRI and SPECT findings were consistent with infarcts at the MCA border zone territory, which were probably related to haemodynamic insufficiency: internal border zone infarction in one patient, and cortical border zone infarction (between anterior cerebral artery and MCA, and between posterior cerebral artery and MCA) in four. Six lesions (50\%) were classified as type A; four (33\%), as type B; and two (17\%), as type C.

\section{Immediate outcomes}

The overall success in reaching the target lesion with stents was $85.7 \%$ (of 14 targets). Two procedures (cases 6 and 10) were abandoned because the tortuosity of the blood vessel made it impossible to manipulate the device. Apart from case 4, all patients were treated with one stent each ( 11 cases; 91.7\%). Pre-procedural stenosis varied from $80 \%$ to $95 \%$ (mean $88 \%$ ), and post-operative residual stenosis varied from $0 \%$ to $15 \%$ (mean $6.5 \%)(p<0.001)$ (fig 2 ). Four patients were complicated. Two patients (cases 1 and 4) had arterial rupture related to morbidity and mortality. In case 4, the target vessel ruptured intraoperatively. Complete coverage of the lesion and emergent rescue of the ruptured vessel required the implantation of a second abutted stent, and the patient recovered with minor neurological deficit. The other patient (case 1) died 3 days later. Of the other two patients, an acute thrombotic occlusion was managed in case 7 by intra-arterial administration of abciximab (Reopro; Centocor, Malvern, PA, USA), but the pre-existing neurological deficit was not aggravated. Case 12, who had distal thrombosis during the procedure, had fixed neurological deficits despite heparinisation. The global morbidity rate related to the procedure was $33.3 \%$ (four of 12 ), and the mortality rate was $8.3 \%$ (one of 12).

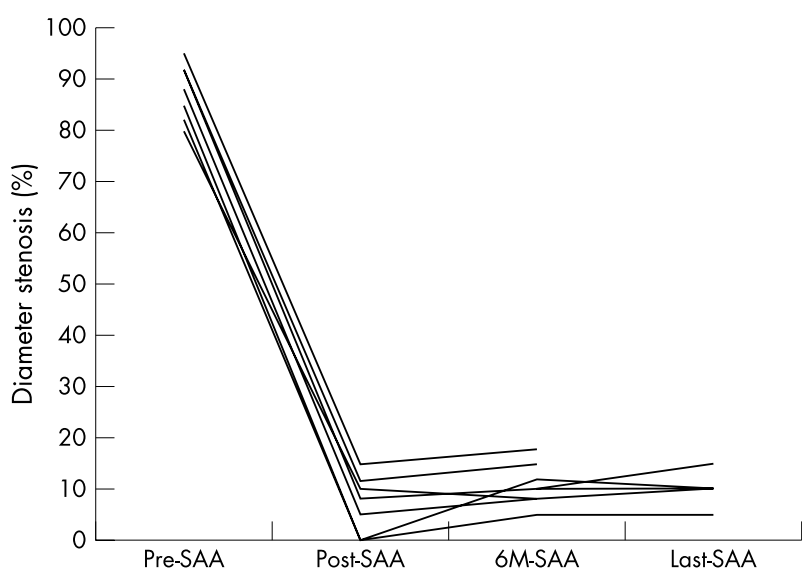

Figure 2 Changes in the diameter of the stenotic middle artery on the angiograms obtained before (pre-SAA) and immediately after (postSAA) treatment and at the 6 month (6M-SAA), and last (Last-SAA) follow ups. There was significant reduction of the stenosis between the pre-operative and post-operative follow up angiograms $(p<0.001$, paired Student's $t$ test). All eight patients who underwent follow up cerebral angiography had no recurrence of stenosis.

\section{Follow up outcomes}

Angiographic follow up varied from 7 to 24 months. No evidence of angiographic in stent de novo stenosis or recurrence of stenosis was seen in all eight cases who were followed up angiographically for at least 6 months. All six patients who underwent follow up cerebral angiography at 12 months had no recurrence of stenosis (fig 2).

Comparing with previous SPECT scans, diffusely decreased perfusion of the cerebral hemisphere was restored and the focal perfusion defect disappeared almost completely in

Table 1 Patient characteristics with middle cerebral artery stenosis and clinical outcome and complications of stent assisted angioplasty

\begin{tabular}{|c|c|c|c|c|c|c|c|c|c|}
\hline Case & Age/sex & $\begin{array}{l}\text { Clinical } \\
\text { presentation }\end{array}$ & Medication & $\begin{array}{l}\text { SPECT } \\
\text { findings }\end{array}$ & $\begin{array}{l}\text { Lesion } \\
\text { type }\end{array}$ & $\begin{array}{l}\text { Stent type and } \\
\text { size }(\mathrm{mm})\end{array}$ & Inflation pressure & $\begin{array}{l}\text { Follow up } \\
\text { SPECT finding }\end{array}$ & Complications \\
\hline 1 & $54 / M$ & Recurrent TIAs & Aspirin & ND & $A$ & GFX $3.5 \times 9$ & $8 \AA$ for 3 seconds & ND & Arterial rupture \\
\hline 2 & $72 / M$ & Recurrent TIAs & Aspirin/clopidogrel & $\begin{array}{l}\text { Perfusion } \\
\text { defect }\end{array}$ & B & S-660 $2.5 \times 9$ & 6 Åfor 20 seconds & $\begin{array}{l}\text { Improved } \\
\text { perfusion }\end{array}$ & None \\
\hline 3 & $62 / F$ & Two strokes & Aspirin/ticlopidine & $\begin{array}{l}\text { Perfusion } \\
\text { defect }\end{array}$ & B & S-660 $2.5 \times 12$ & $6 \AA$ for 15 seconds & No change & None \\
\hline 4 & $42 / F$ & Recurrent TIAs & Aspirin & $\begin{array}{l}\text { Perfusion } \\
\text { defect }\end{array}$ & C & S-660 $2.5 \times 18$ & $\begin{array}{l}6 \AA \text { for } 15 \text { seconds for } \\
3 \text { minutes }\end{array}$ & ND & $\begin{array}{l}\text { Arterial rupture, } \\
\text { thrombosis }\end{array}$ \\
\hline 5 & $68 / M$ & Hemiparesis & Aspirin & ND & A & $\begin{array}{l}\text { S-660 } 2.5 \times 18 \\
\text { S-660 } 2.5 \times 9\end{array}$ & $6 \AA$ for 20 seconds & ND & $\begin{array}{l}\text { Endovascular rescue } \\
\text { None }\end{array}$ \\
\hline 6 & $56 / M$ & Recurrent TIAs & Aspirin & $\begin{array}{l}\text { Perfusion } \\
\text { defect }\end{array}$ & B & - & - & ND & - \\
\hline 7 & $76 / M$ & Two strokes & Warfarin & ND & B & S-660 $2.5 \times 15$ & $6 \AA$ for 20 seconds & ND & Thrombotic occlusion \\
\hline 8 & $56 / M$ & Recurrent TIAs & Aspirin/ticlopidine & $\begin{array}{l}\text { Perfusion } \\
\text { defect }\end{array}$ & A & S-660 2.5×9 & $6 \AA$ for 15 seconds & $\begin{array}{l}\text { Improved } \\
\text { perfusion }\end{array}$ & None \\
\hline 9 & $67 / F$ & Hemiparesis & Warfarin & $\begin{array}{l}\text { Perfusion } \\
\text { defect }\end{array}$ & B & S-660 $2.5 \times 15$ & $6 \AA$ for 20 seconds & $\begin{array}{l}\text { Improved } \\
\text { perfusion }\end{array}$ & None \\
\hline 10 & $70 / \mathrm{F}$ & Two strokes & Clopidogrel & $\begin{array}{l}\text { Perfusion } \\
\text { defect }\end{array}$ & C & - & - & ND & - \\
\hline 11 & $58 / M$ & Recurrent TIAs & Aspirin/clopidogrel & $\begin{array}{l}\text { Perfusion } \\
\text { defect }\end{array}$ & $A$ & S-660 $2.5 \times 9$ & $6 \AA$ for 10 seconds & $\begin{array}{l}\text { Improved } \\
\text { perfusion }\end{array}$ & None \\
\hline 12 & $62 / \mathrm{F}$ & Hemiparesis & Warfarin/aspirin & $\begin{array}{l}\text { Perfusion } \\
\text { defect }\end{array}$ & C & S-660 $2.5 \times 18$ & $5 \AA$ for 30 seconds & ND & Distal thrombosis \\
\hline 13 & $67 / M$ & Hemiparesis & Aspirin/ticlopidine & $\begin{array}{l}\text { Perfusion } \\
\text { defect }\end{array}$ & A & S-660 $2.5 \times 9$ & $6 \AA$ for 20 seconds & No change & None \\
\hline 14 & $58 / \mathrm{F}$ & Recurrent TIAs & Aspirin & $\begin{array}{l}\text { Perfusion } \\
\text { defect }\end{array}$ & A & S-660 $2.5 \times 9$ & $6 \AA$ for 10 seconds & $\begin{array}{l}\text { Improved } \\
\text { perfusion }\end{array}$ & None \\
\hline
\end{tabular}

Medication: pre-operative medication (antiplatelets and/or anticoagulants).

Lesion type: classified according to the method of Mori et al. ${ }^{8}$

ND, not done; TIAs, transient ischaemic deficits; complication, periprocedural and post-procedural complications; endovascular rescue, arterial rupture was rescued by balloon tamponade and additional overlapping stenting.

Thrombotic occlusion was treated with intra-arterial administration of abciximab (Reopro; Centocor, Malvern, PA).

Cases 6 and 10 had unsuccessful stent assisted angioplasty owing to the tortuouity of the internal carotid artery siphon. 
follow up SPECT scans of all four patients with TIAs (fig 1). In three stroke patients who underwent follow up SPECT, improved perfusion was demonstrated in only one; the remaining two showed no improvement (table 1).

The clinical follow up period varied from 3 to 27 months (mean 11 month). Good short term clinical outcomes of the successful stent assisted angioplasties were achieved in eight patients $(66.7 \%)$. None of the five patients (cases 2, 4, 8, 11 , and 14) who had had recurrent TIAs developed additional TIAs during the follow up period. None of the six patients (cases 3, 5, 7, 9, 12, and 13) who had had one or more stroke attacks developed additional ischaemic stroke during the follow up period. On the modified Rankin Scale applied in follow up, 4/5 TIA patients and 5/6 stroke patients who underwent the successful procedure were assessed as functionally improved or of stable clinical status. Of the five stroke patients (cases 3, 5, 7, 9, and 13) who had clinically stable or improved status, one (case 5) showed clinical improvement at discharge (the motor dysfunction resolved), one (case 9) revealed motor improvement over a 6 month period, and the remaining three (cases 3, 7, and 13) did not show any clinical improvement during follow up. The TIA group had relatively poorer prognosis than the stroke group (fig 3). No patient died during the follow up period. Of the two patients where surgery had failed to gain access to the MCA because of the tortuosity of the ICA siphon, one patient (case 6), who had experienced TIAs, developed a complete MCA infarction 9 months after discharge. The other stroke patient (case 10) was clinically stable up to the 1 year follow up.

\section{DISCUSSION}

The natural history of intracranial stenoses has not been as well studied as that of extracranial stenoses, but they are consistently associated with a high stroke rate. ${ }^{18}{ }^{19}$ Stenoses of the MCA occur at a rate of at least $8 \%$ per year. ${ }^{3}{ }^{4}$ This study by Bogousslavsky et al ${ }^{3}$ revealed that $58 \%$ of the Asian population enrolled in the extracranial-intracranial (EC-IC) bypass study were eligible for the MCA arteriosclerosis study, whereas only $34 \%$ of blacks and only $18 \%$ of whites were eligible, emphasising the ethnic differences in this disease. Only about one third of patients had a warning TIA prior to stroke; the remaining two thirds did not. ${ }^{320}$

Management of these high risk patients is controversial. Recently, PTA has been performed in patients refractory to medical treatment, and several reports have been published

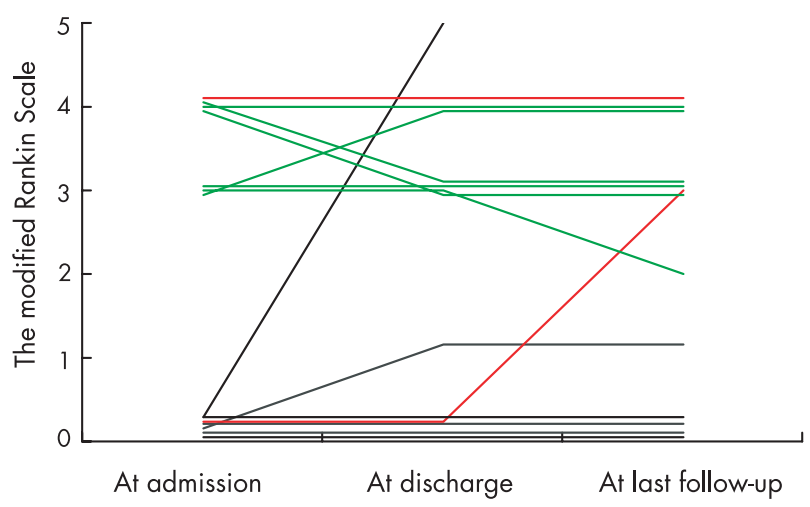

Figure 3 Clinical outcome on the modified Rankin Scale. The transient ischaemic deficits group (black lines) had relatively poorer prognosis than the stroke group (green lines). However, there was a generally stable or improved clinical status after stent assisted angioplasty. Red lines indicate the clinical course of two patients in whom surgery was unsuccessful due to the tortuous curve of the internal carotid artery siphon. One patient who had experienced transient ischaemic deficits developed a complete middle cerebral artery infarction 9 months after discharge. concerning the usefulness of angioplasty in the treatment of arteriosclerotic stenosis of the MCA. ${ }^{6-8}{ }^{21}$ However, compared with extracranial vessels, angioplasty of intracranial vessels has a higher complication rate. PTA has had problems of abrupt closure owing to complications such as intimal damage, elastic recoil, and thrombosis. Mori et al $l^{8}$ reported a clinical success rate of $92 \%, 86 \%$, and $33 \%$ for PTA of intracranial lesions of Type A, B, and C, respectively. At 1 year follow up, rates of stenosis recurrence of $0 \%, 33 \%$, and $100 \%$, respectively, were seen. Stent placement for refractory intracranial stenosis has been developed because of suboptimal long term results after balloon angioplasty alone. Although no evidence exists to demonstrate the superiority of stent placement over angioplasty alone in the intracranial circulation, available data indicate that it is superior for coronary vessels of similar calibre to the intracranial vessels. In one study of 43 lesions in coronary vessels less than $2.5 \mathrm{~mm}$ in calibre, $76 \%$ of patients remained symptom free or had patent target sites after coronary artery stent placement. ${ }^{22}$ Theoretically, stenting minimises the risk of acute closure caused by compression of the intimal flap, and in trapping plaque material between the stent and the vessel wall, can act as a barrier to platelet aggregation of plaque. The risk of vessel rupture may also be reduced, as the stent may provide additional wall support. Therefore, stenting is considered the better tool for vascular recanalisation than PTA.

The purpose of stent assisted angioplasty should be to provide sufficient perfusion to reduce ischaemic symptoms, not to provide an angiographic cure. ${ }^{23}$ Improved clinical outcome was defined as 'stable or improved neurological status and resolution of progressive or recurring symptoms'. Considering that none of the five patients with recurrent TIAs and none of the six patients who had experienced one or more stroke attacks developed TIAs or additional ischaemic stroke during the follow up period, there appears to be a therapeutic efficacy of stenting. The clinical improvement might have been related to improved perfusion to the ischaemic penumbra zone or developed collateral circulation in the stroke patients. SPECT scans demonstrated improved baseline cerebral perfusion and marked augmentation of cerebral blood flow in the MCA distribution after acetazolamide administration. ${ }^{24}$ In our study, follow up brain SPECT of four patients with TIA showed improved perfusion in the MCA region. Improved regional blood flow was demonstrated in SPECT despite the one documented stroke patient. It is possible that stent assisted angioplasty might have resulted in development of new collateral channels. Other benefits of revascularisation include reduced stroke risk as a result of normalisation of oxygen extraction fraction and increased cerebral blood flow. ${ }^{25}$ In our series, most patients with TIAs had improvement in their ischaemic symptoms immediately after stenting and had augmented cerebral flow, which was demonstrated by cerebral arteriography and SPECT.

Problems with stenting are re-stenosis and acute occlusion. Clearly, stenting of smaller vessels is accompanied by a greater potential for recurrence of stenosis. In our study, there was no recurrence during a short term follow up period. However, there are few reports in the literature concerning intracranial stent patency. The accumulative experience with coronary artery stenting of a small calibre tube $(<2.5 \mathrm{~mm})$ is very important in understanding the fate of the stent in the proximal portion of the MCA. The results of the Stent Restenosis Study for coronary vessels stenosis $(<3 \mathrm{~mm})$ showed a stenosis recurrence rate of $50 \%$ or more in $55 \%$ of the angioplasty group and in $34 \%$ of the group receiving stents. $^{26}$ Small vessel stenting for coronary vessels is associated with a higher stenosis recurrence rate and worse 
event free survival rate. ${ }^{27}{ }^{28}$ Additionally, the smaller lumen of the vessel increases the likelihood of acute thrombosis with complicating ischaemia. We experienced several complications of arterial rupture and thrombosis related to mortality and morbidity. Balloon overdilation is not an accepted practice in the intracranial circulation, and it may be especially dangerous in the basilar artery or the MCA, where different authors advocate underdilation because of the insubstantial muscularis and adventitial layers of the artery wall and the subsequent elevated risk of perforation. ${ }^{21}$ The S660 stent we used was a balloon expandable stent and its nominal pressure was $8 \AA$, but the balloon was inflated to a maximum pressure of $6 \AA$ to ensure stent detachment in our series.

\section{CONCLUSIONS}

Although the rate of stenosis recurrence in stent assisted angioplasty in our study seems to be better than that for PTA reported previously, the complication rate of stent assisted angioplasty is higher than the known annual risk of ipsilateral stroke. Although elective stenting is a worthwhile therapeutic method for the prevention of secondary ischaemic stroke in strokes, it seems to be a potentially effective but also hazardous therapeutic technique in patients with recurrent TIAs due to MCA stenosis. Long term follow up data and additional clinical experience are required to properly assess this novel approach for treatment of MCA stenosis. Whether this will lead to better outcomes and reduce stroke risk for MCA stenosis in the future remains unclear. It indicates the need for randomised control trial data of this intervention.

\section{Authors' affiliations}

J Y Ahn, Y S Chung, S S Chung, Department of Neurosurgery, Pundang CHA Hospital, College of Medicine, Pochon CHA University, 351

Yatapdong, Pundangku, Sungnam 463-712, Korea

B H Lee, Department of Radiology, Pundang CHA Hospital, College of Medicine, Pochon CHA University, 351 Yatapdong, Pundangku, Sungnam 463-712, Korea

O J Kim, W C Kim, Department of Neurology, Pundang CHA Hospital, College of Medicine, Pochon CHA University, 351 Yatapdong, Pundangku, Sungnam 463-712, Korea

J K Kim, Graduate School of Life Science and Biotechnology, Pundang CHA Hospital, College of Medicine, Pochon CHA University, 351 Yatapdong, Pundangku, Sungnam 463-712, Korea

J Y Joo, Department of Neurosurgery, Yonsei University College of Medicine, 146-92, Dogok-dong, Gangnamgu, Seoul 135-720, Korea Competing interests: none declared

\section{REFERENCES}

1 Caplan LR, Gorelick PB, Hier DB. Race, sex and occlusive cerebrovascular disease: a review. Stroke 1986;17:648-55.
2 Li H, Wong KS. Racial distribution of intracranial and extracranial atherosclerosis. J Clin Neurosci 2003;10:30-4.

3 Bogousslavsky J, Barnett $\mathrm{HJ}$, Fox AJ, et al. Atherosclerotic disease of the middle cerebral artery. Stroke 1986;17:1112-20.

4 The Extracranial Intracranial Bypass Study Group. Failure of extracranialintracranial arterial bypass to reduce the risk of ischemic stroke. Results of an international randomized trial. N Engl J Med 1985;313:1191-200.

5 Connors JJ III. Intracranial angioplasty. In: Connors JJ III, Wojak JC, eds. Interventional neuroradiology. Philadelphia: Saunders Co, 1999:500-50.

6 Lee JH, Kwon SU, Lee JH, et al. Percutaneous transluminal angioplasty for symptomatic middlle cerebral artery stenosis: long-term follow-up. Cerebrovasc Dis 2003; 15:90-7.

7 Marks MP, Marcellus M, Norbash AM, et al. Outcome of angioplasty for atherosclerotic intracranial stenosis. Stroke 1999;30:1065-9.

8 Mori T, Fukuoka M, Kazita K, et al. Follow-up after intracranial percutaneous transluminal cerebral balloon angioplasty. AJNR Am J Neuroradiol $1998 ; 19: 1525-33$

9 Kimura T, Yokoi H, Nakagawa Y, et al. Three-year follow-up after implantation of metallic coronary artery stents. N Engl J Med 1996;334:561-6.

10 Lylyk P, Cohen JE, Ceratto R, et al. Angioplasty and stent placement in intracranial atherosclerotic stenosis and dissections. AJNR Am J Neuroradiol 2002;23:430-6.

11 Al-Mubarak N, Gomez CR, Vitek JJ, et al. Stenting of symptomatic stenosis of the intracranial internal carotid artery. AJNR Am J Neuroradiol 1998; 19:1949-51.

12 Gress DR, Smith WS, Dowd CF, et al. Angioplasty for intracranial symptomatic vertebrobasilar stenosis. Neurosurgery 2002;51:23-9.

13 Levy El, Hanel RA, Bendok BR, et al. Staged stent-assisted angioplasty for symptomatic intracranial vertebrobasilar artery stenosis. J Neurosurg 2002; 97:1294-301.

14 Mori T, Kazita K, Mori K. Cerebral angioplasty and stenting for intracranial vertebral atherosclerotic stenosis. AJNR Am J Neuroradiol 1999;20:787-9.

15 Chimowitz MI, Kokkinos J, Strong J, et al. The Warfarin-Aspirin Symptomatic Intracranial Disease Study. Neurology 1995;45:1488-93.

16 Samuels OB, Joseph GJ, Lynn MJ, et al. A standardized method for measuring intracranial arterial stenosis. AJNR Am J Neuroradiol 2000;21:643-6.

17 van Swieten JC, Koudstaal PJ, Visser MC, et al. Inter-observer agreement for the assessment of handicap in stroke patients. Stroke 1988;19:604-7.

18 Akins PT, Pilgram TK, Cross DT 3rd, et al. Natural history of stenosis from intracranial atherosclerosis by serial angiography. Stroke 1998;29:433-8.

19 Wong KS, Li H, Lam WW, et al. Progression of middle cerebral artery occlusive disease and its relationship with further vascular events after stroke. Stroke 2002;33:532-6.

20 Caplan L, Babikian V, Helgason C, et al. Occlusive disease of the middle cerebral artery. Neurology 1985;35:975-82.

21 Suh DC, Sung KB, Cho YS, et al. Transluminal angioplasty for middle cerebral artery stenosis in patients with acute ischemic stroke. AJNR Am J Neuroradiol 1999;20:553-8.

22 Huang $P$, Levin T, Kabour A, et al. Acute and late outcome after use of 2.5$\mathrm{mm}$ intracoronary stents in small $(<2.5 \mathrm{~mm})$ coronary arteries. Catheter Cardiovasc Interv 2000;49:121-6.

23 Gomez CR, Misra VK, Campbell MS, et al. Elective stenting of symptomatic middle cerebral artery stenosis. AJNR Am J Neuroradiol 2000;21:971-3.

24 Fessler RD, Lanzino G, Guterman LR, et al. Improved cerebral perfusion after stenting of a petrous carotid stenosis: technical case report. Neurosurgery 1999;45:638-42.

25 Uchiyama N, Kida S, Watanabe T, et al. Improved cerebral perfusion and metabolism after stenting for basilar artery stenosis: technical case report. Neurosurgey 2001;48:1386-92.

26 George CJ, Baim DS, Brinker JA, et al. One-year follow-up of the Stent Restenosis (STRESS I) Study. Am J Cardiol 1998;81:860-5.

27 Elezi S, Kastrati A, Neumann FJ, et al. Vessel size and long-term outcome after coronary stent placement. Circulation 1998;98:1875-80.

28 Hsieh IC, Chien CC, Chang HJ, et al. Acute and long-term outcomes of stenting in coronary vessels $>3.0 \mathrm{~mm}, 3.0-2.5 \mathrm{~mm}$, and $<2.5 \mathrm{~mm}$. Catheter Cardiovasc Interv 2001;53:314-32. 